\title{
The differential involvement of subcortical nuclei in senile dementia of Alzheimer's type
}

\author{
G K WILCOCK, ${ }^{*}$ M M ESIRI, $\dagger$ D M BOWEN, $\ddagger$ A O HUGHES
}

From the Department of Care of the Elderly, Frenchay Hospital,* Bristol, Department of Neuropathology, Radcliffe Infirmary, Oxford, $\dagger$ Department of Neurochemistry, Institute of Neurology, London, $\ddagger$ and Department of Epidemiology \& Community Medicine, University of Bristol,§ Bristol, UK

SUMMARY Cell counts have been performed on cholinergic subcortical nuclei, dorsal raphe nucleus, and locus caeruleus from up to 18 cases of Alzheimer's disease and 10 age-matched control subjects. In general, the extent of the cell loss in these structures was similar. In the basal nucleus the anteromedial subdivision was the least, and the posterior subdivision the most affected. A subgroup of demented subjects with Alzheimer's disease had a relatively preserved basal nucleus, and frontal lobe (CAT) choline acetyltransferase activities similar to those in control subjects, but significantly more neuronal loss in the locus caeruleus.

Neuropathological changes in the neocortex of subjects with Alzheimer's disease are known to be accompanied by a reduction in certain neurotransmitter substances or their marker enzymes, and this has stimulated examination of the subcortical sites associated with their synthesis. The nucleus basalis of Meynert (NBM) in the substantia innominata (together with the medial septal nucleus (MSN) and the nucleus of the diagonal band of Broca (DBB)) is the predominant cholinergic source, and has been shown to be affected by neuronal loss and other histological features of Alzheimer's disease since the early studies of Pilleri. ${ }^{2}$ Others have also described the presence of neurofibrillary tangles in the NBM.$^{3-7}$ The neuronal loss in the basal forebrain in particular has been confirmed by many studies using either cresyl violet stained material ${ }^{58-10}$ or more specific stains for cholinergic marker enzymes such as choline acetyltransferase (CAT), ${ }^{71112}$ and the loss of larger neurons has been reported to be as great as $90 \%$ in some cases. Pearson et al,$^{13}$ however, using a monoclonal antibody staining technique for CAT failed to demonstrate a significant loss of cholinergic cells from the NBM, but rather a shrinkage of neuronal perikarya. In a detailed study dividing the NBM into six subpopulations adapting Mesulam's nomenclature from the monkey to man, ${ }^{14}$ Arendt and his colleagues reported an average overall loss of neurons of $57 \%$, with the most extensive loss occurring in the posterior

Address for reprint requests: Professor G K Wilcock, Department of Care of the Elderly, Frenchay Hospital, Bristol, BS16 1LE, UK.

Received 14 July 1987 and in revised form 12 January 1988. Accepted 21 January 1988 part of the nucleus in three of their five cases. However, all subjects showed an individual pattern of NBM degeneration. ${ }^{15}$ They also found that there was a significant correlation between the degree of cell loss and the number of neocortical senile plaques.

The locus caeruleus (LC) is the main subcortical site for the synthesis of noradrenaline and its precursor enzymes. Reduction in the number of pigmented neurons in this structure in Alzheimer's disease has been demonstrated in several studies since $1978,{ }^{16-19}$ and the extent of the cell loss been shown to correlate with the severity of the dementia and neurofibrillary tangle and senile plaque formation, ${ }^{1725}$ although this has not been found in all studies. ${ }^{20}$ The central portion of the locus caeruleus, which is considered to project predominantly to the temporal cortex and hippocampus, that is, areas of cortex which are usually severely affected by neurofibrillary tangle and senile plaque formation, has been reported to show the most extensive loss of cells. ${ }^{21}$

The serotoninergic dorsal raphe nuclei (DRN) have been less extensively examined, although neurofibrillary tangle formation and neuronal loss have also been described in these structures. ${ }^{41822-24}$

Few studies have compared the changes in different subcortical structures in each of an age-matched series of brains from subjects with Alzheimer's disease and undemented control subjects. Mann and colleagues examined the NBM, the LC and the DRN and the substantia nigra, and reported that the greatest cell loss occurred in the locus caeruleus with a strong correlation between cortical plaque and tangle counts, and nerve cell atrophy and loss in all four areas. $^{25}$ However, in this study they used material 
from one set of control subjects for the locus caeruleus and substantia nigra comparisons, and a different subset of control subjects for comparison of the NBM and raphe nuclei changes. In addition, in this and earlier studies, ${ }^{26}$ in common with some of the other reports mentioned above, they have examined the dorsal tegmental nucleus (DTN; also called supratrochlear nucleus) as representative of the serotinin (5HT) containing nerve cells of the upper brain stem. The nomenclature of the nuclei in this region is confusing, but these more laterally placed neurons, although merging medially with the DRN, are not considered to be serotoninergic, ${ }^{27-30}$ but rather project to the mamillary nucleus of hypothalamus. We report here, therefore, the results of a study examining neuronal loss in the dorsal raphe nucleus (excluding the more laterally placed cells of the dorsal tegmental nucleus), the locus caeruleus, the subdivisions of the nucleus basalis and the nucleus of the diagonal band, as described by Arendt et al, ${ }^{15}$ and the relationship between cortical changes and cell loss in some of these structures. We originally intended to include in our study an examination of the changes in the medial septal nucleus, but discovered that this group of cells is not readily identifiable in man, as has been reported elsewhere. ${ }^{31}$

\section{Methods}

We examined material from 18 patients with Alzheimer's disease or senile dementia of Alzheimer's type and 10 agematched control subjects, all of whom were assessed prospectively for the presence or absence of dementia. The diagnostic criteria employed are described in detail elsewhere, as are the histological criteria for confirming the diagnosis of Alzheimer's disease, the techniques used in quantifying the numbers of plaques and tangles in the cortex, and the biochemical procedures employed to assay cortical CAT levels. ${ }^{3233}$ Histological examination of the nucleus basalis was undertaken in the right hemisphere, the left having been frozen for biochemical studies. In some subjects material was not available from all the subcortical and cortical areas studied, and therefore the mean age and range of ages varies slightly from group to group, and are described separately for each section below.

\section{Cholinergic subcortical nuclei}

Material was available from 13 patients with Alzheimer's disease, median age 79 years (range 51-91 years) and seven control subjects median age 83 years (range 55-102 years). The nucleus was subdivided using a modification of Arendt's method $^{15}$ as described below and cells were counted in $20 \mu \mathrm{m}$ thick cresyl violet stained sections if they had prominent Nissl substance, a nucleolus and a maximum diameter of 30 $\mu \mathrm{m}$ or greater, except in the NDB, where the maximum diameter employed was $20 \mu \mathrm{m}$; the cells here tended to be smaller than in the NBM itself, as has also been reported by others. $^{31}$ Cell counts were made in the vertical part of the NDB in one field $\left(0.3 \mathrm{~mm}^{2}\right)$ from each of the five areas of greatest cell density in the section where the nucleus was most prominent. The three highest counts were used in the analysis. The anterior subdivision of the NBM $(\mathrm{CH} 4 \mathrm{a})$ was examined in a section at the level where a vascular structure divides the cells into medial and lateral groups (CH4am; $\mathrm{CH} 4 \mathrm{al}$ ) and all cells in this section were counted, the number for each group being recorded separately. A section was examined from the intermediate part of the nucleus (CH4i) at a level half way through the supraoptic nucleus where one field from each of the five areas of maximum cell density was counted, and the three highest counts used in the analysis. A section was examined from the posterior part (CH4p) of the NBM at a level two-thirds of the way through the remainder of the nucleus, where all the cells observed were counted.

\section{Locus caeruleus and dorsal nucleus of the raphe}

A brain stem block was taken from the level of the superior colliculus to approximately one-third of the way through the pons, that is, to a point a little caudal to the emergence of the trochlear nerve. Examination of the locus caeruleus was possible in 13 patients with Alzheimer's disease, median age 78 years (range 55-89 years), and in 10 control subjects with a median age of 80 years (range 55-102 years). All the nucleolated, pigmented neurons were counted, and each side recorded separately from a $20 \mu \mathrm{m}$ thick cresyl violet stained section taken at each of five levels, that is $1 / 6,1 / 3,1 / 2,2 / 3$, and $5 / 6$ ths of the way through the LC.

The dorsal raphe nucleus was examined in material from 12 patients with Alzheimer's disease, median age 78 years (range 55-89 years), and nine control subjects, median age 80 years (range 55-102 years) using a $20 \mu \mathrm{m}$ cresyl violet stained section at a level half way through the trochlear nucleus. In order to exclude cells of the dorsal tegmental nucleus (supratrochlear nucleus), all nucleolated neurons containing Nissl substances were counted in three adjacent fields (area 0.3 $\mathrm{mm}^{2}$ ) on each side of the midline along a line passing from the upper border of the median longitudinal bundle to the aqueduct, and in two fields in the midline between the medial borders of the median longitudinal bundle, and this sample of the DRN used for the comparison between the two groups.

All sections were numbered before quantification and analysis so that all counting could be undertaken without knowledge of the patient or the diagnosis.

Review of the data before analysis showed distributions of variables far from symmetrical. This, together with the small sizes of the samples involved, suggested a non-parametric approach, and hence medians are quoted in place of mean values. Tests of significance involved Mann-Whitney U tests or Friedman two-way analysis of variance, and are all based on one-tailed probability levels, it being hypothesised that the disease would only lead to a decrease in cell counts. Correlations were assessed using Spearman's rank correlation coefficient. Computation was aided by the use of the Statistical Package for Social Scientists Version X.

\section{Results}

\section{Cholinergic system}

(a) Effect of age Table 1 shows the age, frontal and temporal lobe CAT levels, and the mean neuronal counts per field for each of the four subdivisions of the basal nucleus and the nucleus of the diagonal band. It 
can be seen that there is no consistent reduction in neuronal number in the NBM with increasing age in the seven control patients. We were only able to obtain neuronal counts from the NDB in four control subjects, but in this small number there is a suggestion of an age related loss of neurons.

(b) Cell loss It can also be calculated from table 1 that there is a reduction in the total number of neurons in the NBM in the demented subjects, and similarly a loss in the NDB. The median for the total cell counts in the NBM in the control subjects is 374 (range 299-477) and for the demented subjects is 230 (range 111-527), which is significant at a level of $p<$ 0.05 (Mann-Whitney $U=17.0$ ), that is, a reduction of the order of $39 \%$. In the NDB the median of the total counts for each of the four control subjects is 145 (range 70-245), compared with 79 (range 60-124) in the 10 demented subjects, which is not significant.

We also gained the impression that more smaller cells which did not reach the size criteria for counting were present in the demented than in the control subjects.

We examined the changes in cell numbers in individual areas within the NBM, and the results are shown in table 2. There was no significant loss in the demented subjects within level CH4am, where the number of cells present in the fields included in the analysis was $87 \%$ of the control values. Most affected were $\mathrm{CH} 4 \mathrm{p}$ and $\mathrm{Ch} 4 \mathrm{al}$ with counts that were $43 \%$ and $48 \%$ respectively of the counts in the undemented controls. In the intermediate portion of the nucleus the demented subjects had cell counts that were $59 \%$ of those in normal subjects. These differences, that is, for $\mathrm{CH} 4 \mathrm{p}, \mathrm{CH} 4 \mathrm{al}$ and $\mathrm{CH} 4 \mathrm{i}$ were all significant at a level of at least $\mathrm{p}<0.05$.

(c) Biochemical relationships The median frontal lobe CAT levels in the six control subjects for which it was available was $7.29 \mathrm{nmol} / \mathrm{min} / 100 \mathrm{mg}$ (range 6.6-9.93), compared with $4.63 \mathrm{nmol} / \mathrm{min} / 100 \mathrm{mg}$ (range $0.85-8.63$ ) in 12 of the 13 demented subjects in

Table 1 Cortical biochemistry, histology and cell counts at cholinergic subcortical sites

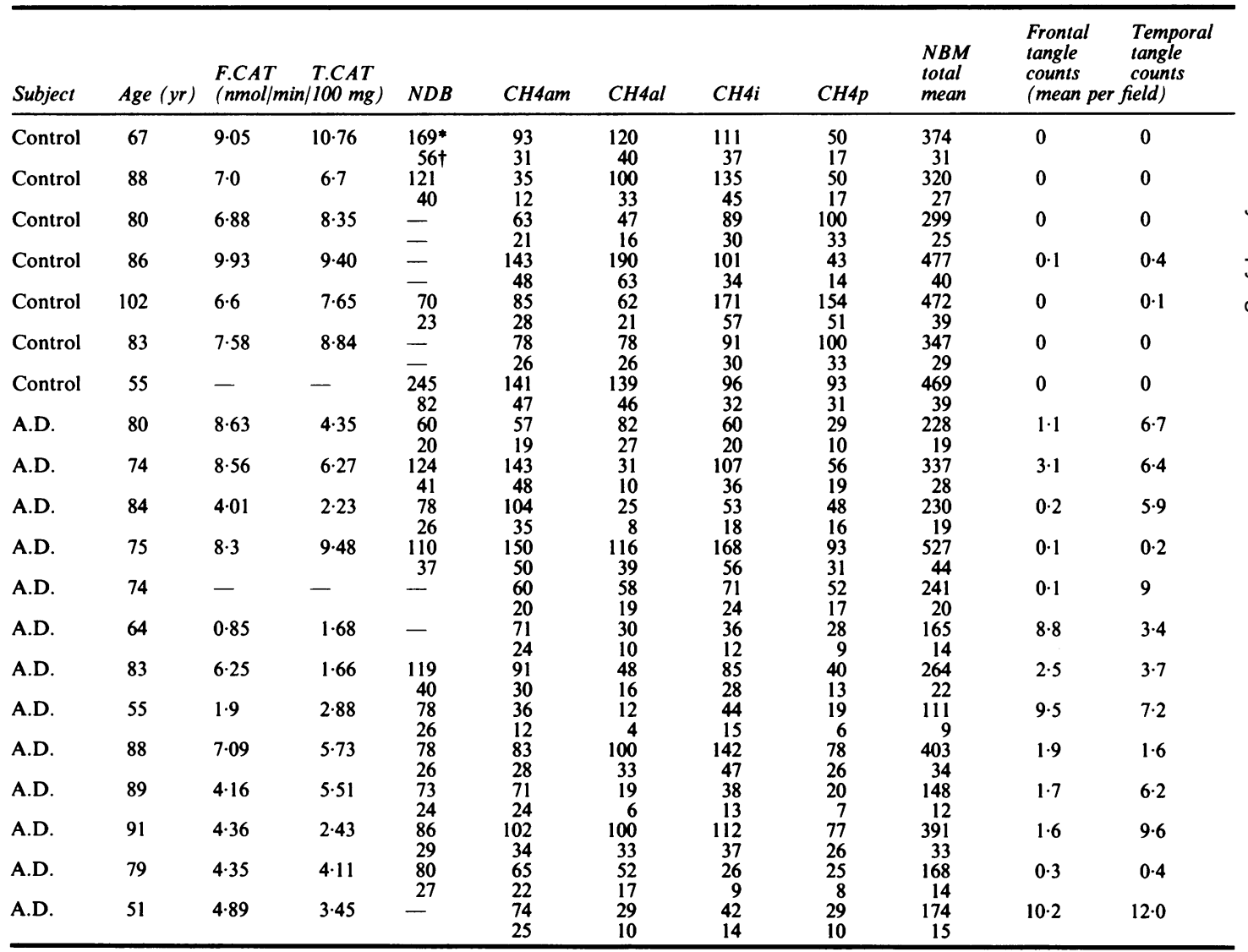

*indicates total number of cells in the fields used in the analyses.

tindicates mean number of cells in the fields used in the analyses. 
Table 2 Differential involvement of NBM subdivisions

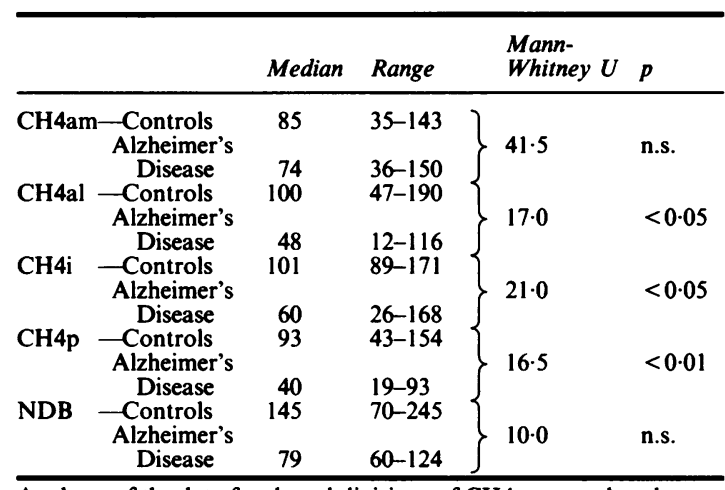

Analyses of the data for the subdivisions of $\mathrm{CH} 4$ were undertaken on seven control subjects and 13 subjects with Alzheimer's disease; for the NDB there were four control and 10 Alzheimer's disease subjects.

whom CAT assays had been undertaken. This difference is significant $(p<0.05$ Mann-Whitney $U$ $=15 \cdot 0$ ). For the temporal lobe the median CAT levels were $8.60 \mathrm{nmol} / \mathrm{min} / 100 \mathrm{mg}$ (range 6.7-10.76) and $3.78 \mathrm{nmol} / \mathrm{min} / 100 \mathrm{mg}$ (range $1.66-9.48$ ) for control and demented subjects respectively, and this reduction in the demented subjects is significant $(\mathrm{p}<0.001$, Mann-Whitney $U=5 \cdot 0$ ).

An approximate "normal" range for frontal lobe CAT suggested on the basis of the levels for the control group might be $5 \cdot 5-10.5 \mathrm{nmol} / \mathrm{min} / 100 \mathrm{mg}$, and it can be seen from table 1 that five of the subjects with Alzheimer's disease had frontal CAT levels lying within this range. Area $\mathrm{CH} 4 \mathrm{al}$ and $\mathrm{CH} 4 \mathrm{i}$ both project to the frontal lobe, and as there is some overlap in these projections we summated the cell counts from both areas to produce a composite cell count (CCC) for each subject and compared this in the subjects with Alzheimer's disease with reduced frontal lobe CAT levels with the CCC in the demented group with "normal" CAT levels. The median CCC for the low CAT group was 71 (range 56-212) and for the "normal" CAT group it was 142 (range 133-284) which is significant at the $1 \%$ level (Mann-Whitney $U=3.0$ ). When we compared the median CCC in the demented group with "normal" CAT levels with the CCC for the normal, non-demented subjects, 142 and 232 respectively, these differences were not statistically significant, and the ranges of counts were almost identical, 133-284 and 136-291.

Spearman rank correlation coefficients were calculated for the relationship between the CCC and the frontal lobe CAT levels and neurofibrillary tangle counts in the demented subjects shown in table 1. A correlation coefficient of $\mathbf{0 . 7 6}$ was obtained for the biochemical relationship, which is significant at the $1 \%$ level, and -0.46 for the relationship with neurofibrillary tangle counts, which did not quite reach statistical significance.
These relationships were also examined in the temporal lobe. A suggested "normal range" for temporal lobe CAT would be $6.0-11.5 \mathrm{nmol} / \mathrm{min} / 100 \mathrm{mg}$. Only two demented subjects had CAT levels in the temporal lobe that were within this range. (See table 1.) The median neuronal counts for $\mathrm{CH} 4 \mathrm{p}$, the area projecting to the temporal lobe, 75 (range 56-93) and 29 (range 19-78) respectively in these two subjects and the other 10 with reduced temporal lobe CAT levels were compared. The difference observed however is not significant. The median $\mathrm{CH} 4 \mathrm{p}$ neuronal count in the two subjects with "normal" temporal lobe CAT levels, 75 is identical to the median for the control subjects, 75 (range 43-154). We were unable to obtain a significant correlation between $\mathrm{CH} 4 \mathrm{p}$ neuron counts and either the CAT levels or the neurofibrillary tangle counts in the temporal cortex.

\section{Locus caeruleus}

The cell counts for each of the five levels examined are shown in table 3. Sections at level five were not available for two of the control subjects. The overall median value calculated from the means for individual control subjects is $69 \cdot 85$ (range 54.5-84.3) and for the demented subjects it is $45 \cdot 0$ (range $21 \cdot 1-57 \cdot 6$ ). This difference is significant at the $0.01 \%$ level (Friedman 2-way ANOVA). It can be seen that in normal subjects there is a trend for average cell counts to decrease with increasing age, and a correlation coefficient of $\mathbf{R}=-0.58$ was obtained, which reaches the $5 \%$ significance level. As the oldest of the control subjects is 102 years, compared with 89 years for the oldest patient in the group of demented subjects, we also calculated the median cell count for each of the two groups, omitting the oldest subject in each group, producing an age range of 55-88 years for both control and Alzheimer subjects. The median counts were 72.5 and 45.2 respectively for the undemented and demented subjects, a difference that is still significant at a level of $\mathrm{p}<0.001$ (Friedman 2-way ANOVA). There was, however, no correlation between the degree of cell loss in the LC and the histological changes in the cortex.

We were able to examine the locus caeruleus in four of the demented subjects with "normal" levels of CAT in the frontal lobe, and in five age-matched controls. Median counts of 72.5 (range 54.5-84.3) and 50.95 (range 45.3-57.6) were obtained for control and demented subjects with "normal" frontal CAT respectively, a difference that is significant at a level of $\mathrm{p}<0.05$ (Mann-Whitney $U=1.0$ ) in contrast to the results obtained for the NBM. When the demented subjects (median age 79.5 years) with the "normal" CAT levels are compared with the demented subjects with reduced frontal CAT (median age 81.5 years), the difference in median counts, 50.95 (range 45.3-57.6) and 38.45 (range $21 \cdot 1-46 \cdot 7$ ) is not significant. Thus all 
Table 3 Cell counts in the locus caeruleus

\begin{tabular}{|c|c|c|c|c|c|c|c|c|c|c|c|c|c|}
\hline \multirow[b]{2}{*}{ Subject } & \multirow[b]{2}{*}{ Age (yr) } & \multicolumn{5}{|c|}{ Left } & \multicolumn{5}{|c|}{ Right } & \multirow[b]{2}{*}{ Total } & \multirow[b]{2}{*}{ Mean } \\
\hline & & 1 & 2 & 3 & 4 & 5 & $I$ & 2 & 3 & 4 & 5 & & \\
\hline Control & 67 & 21 & 56 & 95 & 92 & 71 & 20 & 53 & 94 & 122 & 101 & 725 & $72 \cdot 5$ \\
\hline Control & 75 & 79 & 89 & 42 & 99 & - & 78 & 81 & 50 & 95 & - & $613(8)$ & $76 \cdot 6$ \\
\hline Control & 75 & 46 & 41 & 82 & 93 & - & 38 & 44 & 104 & 72 & - & $520(8)$ & 65.0 \\
\hline Control & 79 & 20 & 104 & 85 & 87 & 82 & 18 & 116 & 80 & 55 & 30 & 677 & $67 \cdot 2$ \\
\hline Control & 83 & 26 & 40 & 60 & 91 & 110 & 20 & 31 & 60 & 93 & 108 & 639 & 63.9 \\
\hline Control & 86 & 20 & 28 & 71 & 72 & 80 & 23 & 40 & 71 & 78 & 62 & 545 & $54 \cdot 5$ \\
\hline Control & 88 & 12 & 41 & 118 & 100 & 86 & 15 & 31 & 120 & 110 & 92 & 725 & $72 \cdot 5$ \\
\hline Control & 102 & 26 & 44 & 41 & 101 & 75 & 26 & 30 & 48 & 98 & 83 & 572 & $57 \cdot 2$ \\
\hline A.D. & 83 & 23 & 27 & 52 & 69 & 29 & 39 & 61 & 68 & 92 & 26 & 486 & 48.6 \\
\hline A.D. & 88 & 18 & 36 & 53 & 75 & 69 & 20 & 45 & 65 & 114 & 38 & 533 & $53 \cdot 3$ \\
\hline A.D. & 84 & 15 & 27 & 51 & 73 & 55 & 14 & 27 & 46 & 77 & 65 & 450 & $45 \cdot 0$ \\
\hline A.D. & 89 & 22 & 36 & 37 & 30 & 39 & 25 & 35 & 37 & 30 & 28 & 319 & 31.9 \\
\hline A.D. & 55 & 14 & 4 & 17 & 20 & 40 & 7 & 5 & 16 & 35 & 53 & 211 & $21 \cdot 1$ \\
\hline A.D. & 77 & 5 & 19 & 37 & 56 & 45 & 3 & 11 & 29 & 38 & 54 & 297 & 29.7 \\
\hline A.D. & 75 & 21 & 20 & 26 & 16 & 30 & 20 & 16 & 40 & 23 & 40 & 252 & $25 \cdot 2$ \\
\hline A.D. & 76 & 26 & 37 & 46 & 58 & 60 & 25 & 45 & 66 & 45 & 45 & 453 & $45 \cdot 3$ \\
\hline A.D. & 78 & 26 & 26 & 24 & 35 & 28 & 30 & 27 & 33 & 35 & 42 & 306 & 30.6 \\
\hline A.D. & 78 & 18 & 34 & 79 & 103 & 53 & 18 & 44 & 67 & 105 & 16 & 537 & 53.7 \\
\hline A.D. & 79 & 20 & 40 & 60 & 57 & 53 & 16 & 34 & 46 & 59 & 82 & 467 & $46 \cdot 7$ \\
\hline A.D. & 74 & 27 & 43 & 89 & 71 & 55 & 9 & 37 & 79 & 86 & 80 & 576 & 57.6 \\
\hline
\end{tabular}

the demented subjects have a reduced cell count in the locus caeruleus. Unfortunately, the age distribution of the subjects studied did not allow adequate age matching to enable this analysis to be undertaken in respect of the demented subjects with normal temporal lobe CAT levels.

\section{Dorsal raphe nucleus}

The cell counts for the DRN are shown in table 4, and it can be seen that in the normal subjects there is no reduction in the cell numbers with increasing age. Nevertheless, the median age for the control and demented subgroups are well matched. The median count for the DRN in the normal subjects is 208 (range 155-319) and for those with Alzheimer's dis-

Table 4 Neuronal counts in the dorsal raphe nucleus

\begin{tabular}{lccc}
\hline Subject & Age $(y r)$ & Total & Mean \\
\hline Control & 55 & 263 & $32 \cdot 9$ \\
Control & 67 & 155 & $19 \cdot 4$ \\
Control & 75 & 197 & $24 \cdot 6$ \\
Control & 79 & 211 & $26 \cdot 4$ \\
Control & 80 & 255 & $31 \cdot 9$ \\
Control & 83 & 169 & $21 \cdot 1$ \\
Control & 86 & 208 & $26 \cdot 0$ \\
Control & 88 & 319 & $38 \cdot 9$ \\
Control & 102 & 167 & $21 \cdot 0$ \\
A.D. & 75 & 163 & $20 \cdot 4$ \\
A.D. & 83 & 120 & $15 \cdot 0$ \\
A.D. & 74 & 189 & $23 \cdot 6$ \\
A.D. & 74 & 139 & $17 \cdot 4$ \\
A.D. & 88 & 138 & 17.3 \\
A.D. & 79 & 120 & $15 \cdot 0$ \\
A.D. & 76 & 199 & 24.9 \\
A.D. & 77 & 78 & $9 \cdot 8$ \\
A.D. & 78 & 247 & 30.9 \\
A.D. & 78 & 144 & $18 \cdot 0$ \\
A.D. & 55 & 87 & $10 \cdot 9$ \\
A.D. & 89 & 130 & $16 \cdot 3$ \\
\hline
\end{tabular}

ease is 138.5 (range 78-247). This difference is significant at $p<0.005$ (Mann-Whitney $U=14.0$ ). If the control subject aged 102 years is omitted from the calculation, the median count for the control subjects rises to 209.5 (range 155-319) which is significantly different from that of the demented subjects at a level of $p<0.005$ (Mann-Whitney $U=$ $11 \cdot 0)$. We were unable to obtain significant correlations between cell losses in the DRN and the neurofibrillary tangle count in the cortex.

The DRN was examined in four of the demented subjects with "normal" frontal lobe CAT levels, and the median count was found to be 163 (range 120-199), lower than that in five age-matched controls, 208 (range 155-319), although this difference is not statistically significant. When compared with three age-matched demented subjects with reduced CAT levels in whom the median count was 120 (range 87-130), the difference was also not significant. As was the case for the analysis in the locus caeruleus, we were unable to examine the relationship for the temporal lobe.

\section{Comparison of the degree of cell loss at different} subcortical sites

This was possible in 14 subjects, seven of whom were undemented (median age 83 years, range 55-102 years), and seven with Alzheimer's disease (median age 79 years, 55-89 years). The median counts in the demented group are expressed as a percentage of those obtained for the control subjects and are shown in table 5. The NDB is omitted as there were only four control cases with this area included. It can be seen that there is little difference between the extent to 
Table 5 Relative involvement of different nuclei

\begin{tabular}{llcll}
\hline $\begin{array}{l}\text { Subcortical } \\
\text { area }\end{array}$ & $\begin{array}{l}\text { * Median } \\
\text { Alzheimer's } \\
\text { disease }\end{array}$ & $\begin{array}{l}\text { * Median } \\
\text { control }\end{array}$ & $\begin{array}{l}\text { Alzheimer's disease as } \\
\text { a \% of control }\end{array}$ \\
\hline CH4am & 28.0 & 28.0 & no change & n.s. \\
CH4al & 16.0 & 33.0 & 48 & p $<0.05$ \\
CH4i & 28.0 & 34.0 & 82 & n.s. \\
CH4p & 13.0 & 31.0 & 42 & p $<0.05$ \\
CH4 all areas & 21.8 & 31.3 & 70 & n.s. \\
LC total & 467 & 725 & 64 & p $<0.01$ \\
DRN total & 16.3 & 26.0 & 63 & p $<0.01$ \\
\hline
\end{tabular}

*Because of the sampling methods employed in different nuclei, the figures for the NBM and its subdivisions quoted here are median cell counts per field, cf table 2 where total counts are given. These figures also differ from those in table 2 as data for the LC and DRN were only available in seven of the Alzheimer cases.

Seven control subjects with a median age of 83 years (range 55-102 years) and seven subjects with Alzheimer's disease, median age 79 years (range 55-89 years) were examined.

which different nuclei are affected, but there is a suggestion that the LC and DRN were marginally more depleted of cells than the NBM. Within the latter, the greatest reductions occurred in subdivisions $\mathrm{CH} 4 \mathrm{al}$ and $\mathrm{CH} 4 \mathrm{p}$.

\section{Discussion}

We have been unable to confirm the finding of others who have reported a loss of cells in the NBM with increasing age in normal individuals, ${ }^{1234}$ but are not alone in this. ${ }^{35}$ The oldest of our undemented subjects, aged 102 years, had cell counts in the NBM which compared favourably with the other control subjects. Where we have used a sampling method employing an analysis of the highest counts in a proportion of the fields counted, it is possible that a bias has been introduced which would tend to minimise the degree of cell loss, if the latter is not evenly distributed throughout the structure being examined. It is however unlikely that this would be sufficient to explain the absence of an age-related trend. The prevalence of dementia rises with age, such that by 80 years as many as $20 \%$ of the population may have some degree of dementia. It is therefore particularly important that all control subjects are prospectively assessed for the absence of dementia to exclude older poeple with undetected, albeit mild dementia, and hence NBM neuronal loss, from being incorrectly classified as normal, thus introducing an age associated bias. All of our elderly control subjects were carefully and extensively assessed prospectively, but it is unclear in many of the other studies reported in the literature how careful the prospective assessment has been. If inadequately undertaken, this could partly explain the difference between our results and those of others. Nevertheless, because the possibility of an age-related neuronal reduction in the NBM is possible, and has been shown in other subcortical sites, especially the locus cae- ruleus, we have matched our demented and control subjects for age.

We report an overall cell loss from the NBM in the demented subjects which is less than that reported by others. $^{681136-39}$ but similar to the $33 \%$ loss of cells reported by Perry and colleagues ${ }^{10}$ in a group of demented subjects of a similar age to ours. It has also been reported elsewhere that older subjects with Alzheimer's disease lose fewer neurons than younger cases. ${ }^{6}$ If we have produced a sampling bias, as described above, the difference between the two groups would be greater, but we believe that some of the lower estimates of cell loss ${ }^{910} 39$ may also be explained by the very variable reduction in cell numbers experienced by different subjects, and the differential involvement of subdivisions within the NBM, in our study ranging from $7 \%$ in area $\mathrm{CH} 4 \mathrm{am}$ to $49 \%$ in area CH4al. A sampling bias, if one exists, could also minimise the difference between the degree of involvement of the NBM and the locus caeruleus, where all cells in the fields examined were counted.

We found that the subdivision projecting to the temporal lobe (CH4p) was one of the most severely afflicted areas, as did Arendt and colleagues, ${ }^{15}$ which reflects the extensive histological and neurochemical involvement of this lobe in the disease process. Areas $\mathrm{CH} 4 \mathrm{al}$ and $\mathrm{CH} 4 \mathrm{i}$, which project to the frontal lobe, were also depleted of neurons, especially $\mathrm{CH} 4 \mathrm{al}$, but contrary to Arendt's report, CH4am was almost unaffected. There is, however, considerable variability in the pattern of cell loss in different individuals, which has led others to speculate that there may be different subgroups within the spectrum of Alzheimer's disease. ${ }^{15}$ The $\mathrm{CH} 4 \mathrm{am}$ subdivision of the NBM projects predominantly to the parietal lobe, which we noted to be less extensively affected by histological change than the temporal and frontal areas, in our group of subjects who are on average significantly older than those in Arendt's study. ${ }^{15}$ His subjects may have had the more aggressive form of the disease associated with younger people, and in whom therefore the parietal lobe may have been more affected. In younger subjects PET studies have also shown the parietal lobe to be more selectively affected, especially posteriorly. ${ }^{40}$ The parietal lobe thus appears to bear the brunt of the disease in presenile subjects, and the temporal lobe in those who are more elderly.

The subjects with frontal CAT levels within the suggested "normal range" had cell counts in the areas of NBM projecting to the frontal lobe that were similar to those in the control group, and significantly higher than those in the group with low CAT levels. This subgroup of demented subjects with "normal" frontal lobe CAT levels and normal NBM cell counts had a significant reduction in the number of neurons in the LC. In the DRN this subgroup had fewer cells, 
but the difference was not statistically significant. However, the number of cases is small. It would seem, therefore, that there is a subgroup of patients with Alzheimer's disease who have relatively high frontal CAT levels and a relatively preserved NBM, but cell loss in the LC. This cannot be explained on the basis of disease severity, as all the patients were severely demented clinically, that is they were too demented to be tested on cognitive rating scales, and totally dependant on others for even the most basic activities of daily living, and severely affected histologically. The comparisons for the LC and the DRN were made on age-matched groups, but in the NBM the subjects with low CAT levels were on average seven years younger than those with "normal" CAT. ithis is, however, also unlikely to explain the difference since if there is a drop in cell numbers with increasing age, the older subjects, that is, those with "normal" CAT, should have been the group with lower cell counts.

A similar finding was observed in the temporal lobe, but in fewer subjects, emphasising the importance of this part of the brain in the majority if not all cases of Alzheimer's disease.

Significant correlations between the number of cells in the NBM and the counts of cortical neurofibrillary tangles, senile plaque counts and CAT levels have been reported by some workers, ${ }^{12152537}$ but not by others. $^{1039}$ The only significant correlation we obtained was that between NBM cell counts and frontal lobe CAT levels.

Mesulam ${ }^{41}$ has criticised the correlation made by Arendt ${ }^{15}$ between NBM cell counts and the cortical changes, for example between areas $\mathrm{CH} 4 \mathrm{p}$ and Brodman area 20 rather than area 22 , but the use of this system can be defended. ${ }^{42}$ Nevertheless, we may not have made appropriate correlations, as our plaque and tangle counts were only available as a single index representing combined quantification of the change in the superior and middle gyri of frontal and temporal lobes, and the CAT levels from areas 9, 46 and 21 . This may also explain the failure to obtain significant correlations reported in other studies, and the same principle may apply to our failure to show a significant relationship between cell loss in the LC and DRN and the cortical histological changes. It must be noted, however, that despite Arendt and colleagues possibly having made correlations between subdivisions of the NBM and cortex in areas that may not have accurately reflected the cortical projections of NBM subdivisions, significant correlations were still obtained. ${ }^{15}$

The well established trend for cell numbers to decrease in the locus caeruleus with increasing age is also shown in our study, but this does not seem to be the case for the DRN. In demented subjects we found a similar degree of cell loss in both the LC and DRN, and in the locus caeruleus there did not appear to be a differential degree of cell loss at different levels. As is the case for the NBM, the LC is topographically organised, involving varying projection patterns for different cell types in different positions within the same field, ${ }^{43}$ rather than a simple organisation of projections relating to the level of a field along its length. Nevertheless, in one report a greater loss of cells was found in the central part of the locus caeruleus ${ }^{21}$ which the authors represent to be the subdivision of the LC that projects specifically to the temporal lobe. We have not been able to confirm a differential involvement for different levels, and cannot explain this difference.

The loss of locus caeruleus cells observed in our study is more modest than that reported in some others ${ }^{253637}$ but there is considerable variation, and in one report seven out of 17 cases of Alzheimer's disease had locus caeruleus cell counts within the normal range,${ }^{17}$ and in another, substantial cell loss was only observed in a third of the older subjects. ${ }^{16}$

Despite the lack of apparent cell loss with increasing age in the DRN in our control subjects, we took the precaution of matching the demented and undemented subjects for age, and found a degree of cell loss similar to that observed in the LC. It is difficult to compare our results with those of others because of their inclusion of the dorsal tegmental nucleus in the area counted, but figures ranging from a $12 \%$ to $77 \%$ loss have been reported, ${ }^{22} 25$ and another study failed to find any overall cell loss, but a reduction in a subpopulation of large polygonal neurons in the demented subjects. ${ }^{24} \mathrm{~A}$ more detailed assessment of which subdivisions of the raphe system are serotoninergic in man and their relative involvement in Alzheimer's disease will be the subject of a separate report.

Counts for the NDB were only available for four control subjects, so we were not able to include this group in the comparison of 14 cases shown in table 5 (in which the figures shown are slightly different from those presented in the earlier tables as they include only a subsection of the subjects studied). Nevertheless, in the Alzheimer's disease subjects the counts were on average $59 \%$ of those of the four control subjects, a figure that is similar to the overall loss of cells in the other areas examined. Such a similar degree of involvement of subcortical sites could indicate that the primary event in this disease is cortical, spreading to involve the deeper structures.

The authors thank the Sir Jules Thorn Charitable Trust for financial support, Mrs C Williams for technical assistance, and Mrs $J$ Green for typing the manuscript. 


\section{References}

1 Pilleri G. Orale Einstellung nach Art des Kluver-Bucy Syndroms bei hirnatrophischen Prozessen. Schweiz Arch Neurol Psychiat 1976;87:286-98.

2 Pilleri G. Kluver-Bucy syndrome in man-a clinico-anatomical contribution to the function of the medial temporal lobe structures. Psychiat Neurol 1966;152:65-103.

3 Hirano A, Zimmerman HM. Alzheimer's neurofibrillary changes: a topographic study. Arch Neurol 1962;7:227-42.

4 Ischii T. Distribution of Alzheimer's neurofibrillary changes in the brain stem and hypothalamus of senile dementia. Acta Neuropathol (Berl) 1966;6:181-7.

5 Whitehouse PJ, Price DL, Clarke AW, Coyle JT, Delong MR. Alzheimer's disease: evidence for selective loss of cholinergic neurons in the nucleus basalis. Ann Neurol 1981;10:122-6.

6 Tagliavini F, Pilleri G. Basal nucleus of Meynert. A neuropathological study in Alzheimer's disease, simple senile dementia, Pick's disease and Huntingdon's chorea. $J$ Neurol Sci $1983 ; 62 ; 243-60$.

7 Rasool CG, Svendsen CN, Selkoe DJ. Neurofibrillary degeneration of cholinergic and non-cholinergic neurons of the basal forebrain in Alzheimer's disease. Ann Neurol 1986; 20:482-8.

8 Whitehouse PJ, Price DL, Struble RG, Clark AW, Coyle JT, Delong MR. Alzheimer's disease and senile dementia: loss of neurons in the basal forebrain. Science 1981;215:1237-9.

9 Wilcock GK, Esiri MM, Bowen DM, Smith CCT. The nucleus basalis in Alzheimer's disease: cell counts and cortical biochemistry. Neuropathol Appl Neurobiol 1983;9:175-9.

10 Perry RH, Candy JM, Perry EK, et al. Extensive loss of choline acetyltransferase activity is not reflected by neuronal loss in the Nucleus of Meynert in Alzheimer's disease. Neurosci Lett 1982;33:311-5.

11 Nagai T, McGeer PL, Peng JH, McGeer EG, Dolman CE. Choline acetyltransferase immunohistochemistry in brain of Alzheimer's disease patients and controls. Neurosci Lett 1983;36:195-9.

12 McGeer PL, McGeer EG, Suzuki J, Dolman CE, Nagai T. Ageing, Alzheimer's disease, and the cholinergic system of the basal forebrain. Neurology 1984;34:741-5.

13 Pearson RCH, Sofronie MV, Cuello AC, et al. Persistence of cholinergic neurons in the basal nucleus in a brain with senile dementia of Alzheimer type demonstrated by immunohistochemical staining for choline acetyltransferase. Brain Res 1983;289:375-9.

14 Mesulam MM, Mufson EJ, Levey AI, Wainer BH. Cholinergic innervation of cortex by the basal forebrain: cytochemistry and cortical connections of the septal area, diagonal band nuclei, nucleus basalis (substantia innominata), and hypothalamus in the rhesus monkey. J Comp Neurol 1983;214:170-97.

15 Arendt T, Bigl V, Tennstedt A, Arendt A. Neuronal loss in different parts of the nucleus basalis is related to neuritic plaque formation in cortical target areas in Alzhemier's Disease. Neuroscience 1985;14:1-14.

16 Forno LS. The locus caeruleus in Alzheimer's Disease. $J$ Neuropathol Exp Neurol 1978;37:614.

17 Tomlinson BE, Irving D, Blessed G. Cell loss in the locus caeruleus in senile dementia of Alzheimer's type. J Neurol Sci 1981;49:419-28.

18 Mann DMA, Yates PO, Marcyniuk B. Monoaminergic neurotransmitter systems in presenile Alzheimer's Disease and in senile dementia of Alzheimer type. Clin Neuropathol 1984;3:199-205.

19 Bondareff W, Mountjoy CQ, Roth M. Selective loss of neurons of origin of adrenergic projection to cerebral cortex (nucleus locus caeruleus) in senile dementia. Lancet 1981;i:783-4.

20 Perry ER, Tomlinson BE, Blessed G, Perry RH, Cross AJ, Crow TJ. Neuropathological and biochemical observations on the nor-adrenergic system in Alzheimer's disease. $J$ Neurol Sci 1981:51:279-87.
21 Marcyniuk B, Mann DMA, Yates PO. Loss of nerve cells from locus caeruleus in Alzheimer's Disease is topographically arranged. Neurosci Lett 1986;64:247-52.

22 Yamamoto T, Hirano A. Nucleus raphe dorsalis in Alzheimer's disease: neurofibrillary tangles and loss of large neurons. Ann Neurol 1985;17:573-7.

23 Tabaton M, Schenone A, Romagnoli P, Mancardi GL. A quantitative and ultrastructural study of the substantia nigra and nucleus centralis superior in Alzheimer's Disease. Acta Neuropathol (Berl) 1985;68:218-23.

24 Curcio CA, Kemper T. Nucleus raphe dorsalis in dementia of Alzheimer's type: neurofibrillary change and neuronal packing density. J Neuropathol Exp Neurol 1984;43:359-68.

25 Mann DMA, Yates PO, Marcyniuk B. Correlation between senile plaque and neurofibrillary tangle counts in cerebral cortex and neuronal counts in cortex and subcortical structures in Alzheimer's disease. Neurosci Lett 1985;56:51-5.

26 Mann DMA, Yates PO. Serotonin nerve cells in Alzheimer's disease. J Neurol Neurosurg Psychiatry 1983;46:96.

27 Carpenter MB, Sutin J. Human Neuroanatomy. Baltimore: Williams and Wilkins, 8th ed. 1983:415-6.

28 Felton DL, Laties AM, Carpenter MB. Monoamine-containing cell bodies in the squirrel monkey brain. Am $J$ Anat 1974;139:153-66.

29 Takeuchi Y, Kimura H, Matsuura T, Sano Y. Immunohistochemical demonstration of the organisation of serotonin neurones in the brain of the monkey. Acta Anat 1982;114: 106-24.

30 Takeuchi Y, Kimura H, Matsuura T, Yonezawa T, Sano Y. Distribution of serotonergic neurones in the central nervous system: a peroxidase-antiperoxidase study with anti-serotonin antibodies. J Histochem Cytochem 1983;31:181-5.

31 Hedreen JC, Struble RG, Whitehouse PJ, Price DL. Topography of the magnocellular basal forebrain system in human brain. $J$ Neuropathol Exp Neurol 1984;43:1-21.

32 Wilcock GK, Esiri MM. Plaques, tangles and dementia: a quantitative study. J Neurol Sci 1982;56:343-56.

33 Wilcock GK, Esiri MM, Bowen DM, Smith CCT. Alzheimer's disease: correlation of the cortical choline acetyltransferase activity with the severity of the dementia and histological abnormalities. J Neurol Sci 1982;57:407-17.

34 Mann DMA, Yates PO, Marcyniuk B. Alzheimer's presenile dementia, senile dementia of Alzheimer type, and Down's syndrome in middle age form an age related continuum of pathological change. Neuropathol Appl Neurobiol 1984;10:185-207.

35 Bondareff W. Age and Alzheimer's disease. Lancet 1983;i: 1447.

36 Mann DMA, Yates PO, Marcyniuk B. A comparison of changes in nucleus basalis and locus caeruleus in Alzheimer's disease. $J$ Neurol Neurosurg Psychiatry 1984;47:201-3.

37 Mann DMA, Yates PO, Marcyniuk B. A comparison of nerve cell loss in cortical and subcortical structures in Alzheimer's Disease. J Neurol Neurosurg Psychiatry 1986;49;310-2.

38 Candy JM, Perry RH, Perry EK, et al. Pathological changes in the nucleus of Meynert in Alzheimer's and Parkinson's disease. J Neurol Sci 1983;59:277-89.

39 Etienne P, Robithaille Y, Wood P, Gauthier S, Nair N, Quirrion $R$. Nucleus basalis neuronal loss, neuritic plaques, and choline acetyltransferase activity in advanced Alzheimer's disease. Neuroscience 1986;19:1279-91.

40 Tamminga CA, Foster NL, Fedio P, Bird ED, Chase TN. Alzheimer's disease: low cerebral somatostatin levels correlate with impaired cognitive function and cortical metabolism. Neurology 1987;37:161-5.

41 Mesulam MM. Alzheimer's plaques and cortical cholinergic innervation. Neuroscience 1986;17:275-6.

42 Arendt T, Bigl V. Alzheimer's plaques and cortical cholinergic innervation. Neuroscience 1986;17:277-9.

43 Loughlin SE, Foote SL, Grzanna R. Efferent projections of nucleus locus caeruleus: morphological subpopulations have different efferent targets. Neuroscience 1986;18:307-19. 